\title{
Temas dramatúrgicos sobre Teatro de Objetos: o Retorno a Juberlano
}

\section{Dramatic subjects about Theater of Objects: The Return to Juberlano}

Caroline Holanda ${ }^{1}$ 


\section{Resumo}

O Grupo Ânima de Teatro de Animação, dirigido por Tatiane Souza e Cleomir Alencar, inicia uma investigação no campo do Teatro de Objetos, na qual tomo lugar na função de dramaturgista, como uma interlocutora da pesquisa. Falando, portanto, a partir dessa experiência, me proponho neste artigo a estabelecer algumas reflexões que tocam a dramaturgia no Teatro de Objetos, dialogando principalmente com concepções e procedimentos utilizados na Dança Contemporânea, no movimento de tentar identificar, especificidades constitutivas das dramaturgias nesse campo do Teatro de Animação.

Palavras-chaves: Dramaturgista; dramaturgia; dança; teatro de objetos

\section{Abstract}

The Anima Group of Puppetry Theater, directed by Tatiane Souza and Cleomir Alencar, begins an investigation in the field of the Theatre of Objects, in which I take the place as the dramaturgist, as an interlocutor of the research. Speaking, therefore, from this experience, I propose in this article to establish some reflections that touch the dramaturgy in the Theater of Objects, in dialogue mainly with conceptions and procedures used in Contemporary Dance, in a movement of trying to identify, constitutive specificities of dramaturgies in that field of the Puppetry Theatre.

Keywords: Dramaturgist; dramaturgy; dance; theatre of objects

ISSN: 1414.5731

E-ISSN: 2358.6958

${ }^{1}$ Mestre em Teatro pelo Programa de Pós-Graduação em teatro (PPGT), Universidade do Estado de Santa Catarina (UDESC). carolmassinha@yahoo.com.br 


\section{Um lugar de fala: dramaturgista, interlocução poética ou coisa assim...}

Na cidade de Fortaleza, em 2017, são escassas as experiências de pesquisa e montagem espetacular no âmbito do Teatro de Objetos. O Grupo Ânima² de Teatro de Animação, dirigido por Tatiane Souza e Cleomir Alencar, decide colocar em rota seu desejo de investigação nesse campo de atuação, desenvolvendo uma série de ações dentre as quais tornaram-se grupo selecionado pelo Laboratório de Pesquisa Teatral, da Escola Porto Iracema das Artes. Nesse caminho, tomo lugar na função do que a escola chama de tutoria, como uma orientadora do percurso de pesquisa.

A função do tutor pode ser desenhada de diferentes modos. Por vezes parece um diretor, por vezes um assistente de direção, em outras, um interlocutor e no final nos apareceu a função de dramaturgista. É necessário um cuidado ao ocupar esse papel, preocupação em não retirar a força da autonomia necessária à criação autoral. Essa premissa me é cara em qualquer âmbito de formação, sendo mesmo uma perspectiva política - social, docente e artística - sobretudo se falamos do artista contemporâneo.

Esse programa da escola ao qual estivemos vinculados era direcionado a grupos profissionais, o que fortalecia a demanda de uma relação cuidadosamente propositiva sem ser impositiva. Realizei, então, o que venho ensaiando chamar de interlocução poética ${ }^{3}$, na qual o propósito é ajudar a construir a poesia artística do outro, mas a partir dos meios, condições e modos de conduções do artista e não dos meus. Venho realizando esse modo de trabalho com diversos artistas e também estudantes das Universidades de Dança e de Teatro (UFC e UNIFOR) ${ }^{4}$, nas quais fui docente nos últimos 8 anos. Nesse sentido, acabei por tomar consciência de alguns dos movimentos estabelecidos no engendramento dessa função que, como diria o pesquisador Eduardo Passos (2018), funciona mais como o cão-guia que leva o cego não para onde deseja ir, mas leva o cego, às cegas.

$\mathrm{Na}$ interlocução, realizo bastante o trabalho de espelhamento, uma tentativa de devolver elementos encontrados na cena para que o grupo possa decidir o que manter, o que descartar em termos de cena ou de investimento do tempo de pesquisa. Exerço também uma função que chamo de "esfinge", lançando perguntas de ignorância sincera ou de sincera provocação que devem ser respondidas em forma de decisões de percurso pelos artistas. Também compartilho gostos pessoais e outras referências, bem como busco estabelecer um "suporte técnico", no meu caso, muito vinculado à cobrança da coerência entre a ideia perseguida e a qualidade rítmica, cinética e espacial de implementação. Ali também, lanço ideias de possíveis composições intra-cena e por fim, com um material levantado, proponho trabalhos em torno do que chamo "cuidar do gesto" - trabalhar a ampliação da qualidade das cenas - e, experimentar possíveis sequencias de roteiros - estabelecer ordem de cenas em forma de roteiros e experimentar qual parece fazer mais sentido para o trabalho. Nesse momento, todo esse processo nos pareceu alocar uma função de dramaturgista.

\footnotetext{
2 O Ânima é um grupo de Teatro de Animação que atua na cidade de Fortaleza, desde 1998. A investigação dessa linguagem já reverberou em trabalhos com bonecos de luva, boneco popular, teatro de sombras contemporâneo e teatro de objetos.

${ }^{3}$ Esse nome foi, em meu contexto, presente do artista visual Rafael Escócio com o início de uma série se parcerias que realizamos na qual eu exercia interlocução com seus processos de criação.

${ }^{4}$ Universidade Federal do Ceará (UFC); Universidade de Fortaleza (UNIFOR).
} 
A noção de dramaturgista e mesmo a noção de dramaturgia aqui presentes, alinham-se ao pensamento da dança. O dramaturgista, na dança, afasta-se da noção tradicional do dramaturgo do teatro como "aquele que escreve o texto". Na dança, essa figura nasce, enquanto nomeação, bem mais recente que o dramaturgo teatral e tem atuação menos incisiva quanto a moldagem do trabalho. Para a dramaturgista Marianne Van Kerkhoven" (2016, p. 182, grifo nosso):

Creio que o trabalho de um dramaturgista não tem nada a ver com doutrina ou teoria ou com aplicação de regras, pelo contrário; no trabalho dramatúrgico, não se trata de destilar e depois aplicar modelos que adquirimos analisando toda uma série de exemplos práticos ou de representações; é mais precisamente o inverso: é buscar um caminho pelo qual conseguimos "arrumar" e estruturar todo o material que aparece "sobre a mesa" ao trabalharmos numa produção, tentando, sobretudo, "não refazer hoje o que fizemos ontem.

Para ela, cada obra tem seu próprio caminho, ao que a dramaturgista Silvia Soter $^{5}$ (2014) aponta para a necessidade da busca pela constituição dessa relação ética e estética entre dramaturgista e encenador/coreógrafo e/ou atores/intérprete-criadores. Nesse sentido, creio que o trabalho do dramaturgista demanda uma acuidade para dialogar com a obra em questão, procurando construir ferramentas particulares a cada contexto. Do que decorre uma espécie de maleabilidade como característica dessa função, estabelecendo-se muito mais sobre uma postura de diálogo e tateio, que sobre um conjunto de ferramentas fixas. Essa premissa afina-se com uma das posturas mais comentadas entre os escritos acerca do fazer dramaturgista em dança: o gesto de produzir uma espécie de consciência da obra para os artistas. Um movimento fundamental de deixar ao próprio artista o exercício de autonomia sobre seu trabalho. Um gesto artístico, mas antes, um gesto político de fortalecimento das autonomias e das diferenças.

\section{Uma premissa dramatúrgica, um fundamento de linguagem}

Acredito na pesquisa como caminho para o deslocamento dos clichês mais primários da criação, instalando como principal premissa para avanço em terrenos outros, a escuta. Em minha perspectiva docente e artística, a escuta advém questão basal do trabalho cênico, e mais exigentemente no Teatro de Animação. Entendida aqui como um estado corporal de disponibilidade, corroboro com a diretora Anne Bogart, uma das articuladoras do sistema ViewPoints, quando nos apresenta como um fundamento do trabalho do ator, aquilo que chama de escuta extraordinária. Em suas palavras: "Para trabalhar efetivamente no teatro, um campo de ação que exige a colaboração intensa, a capacidade de escutar é o elemento definidor. $E$, no entanto, é muito difícil escutar - realmente escutar"6 (Bogart \& Landau, 2005, p. 32).

Abrangendo um estado de presença e desejo relacionado ao interesse pela investigação e composição cênica, a escuta constitui um movimento de abertura que se ocupa menos de propor e mais de compor em parceria com todo o entorno.

\footnotetext{
${ }^{5}$ Dramaturgista da Lia Rodrigues Companhia de Danças desde 2002.

${ }^{6}$ To work effectively in the theater, a field that demands intense collaboration, the ability to listen is the defining ingredient. And yet, it is very difficult to listen-to really listen. (Tradução nossa).
} 
Essa condição seria o básico do trabalho cênico. No entanto, no Teatro de Animação e ainda mais, no Teatro de Objetos, o caminho percorrido com os materiais pode encontrar um enorme manancial de criação quando a escuta se refina na direção de um verdadeiro diálogo entre homem e matéria. Tal parceria encontra seu terreno mais frutífero quando é possível o desvanecimento de uma simbologia profundamente arraigada no antropocentrismo, aproximando-se de perspectivas menos assimétricas da hierarquização homem-matéria. Nesse sentido, alguns estudiosos em diferentes campos constroem reflexões com base numa compreensão na qual homem e matéria se aproximam enquanto sistemas dinâmicos de diferentes características. $O$ antropólogo Tim Ingold critica um modo de ver matéria-e-objeto como constitutivos de um mundo separado do mundo humano e critica ainda uma visão da matéria como passiva, estacionada e como existente somente quando recebem in-formação humana. Seu pensamento toma relevo aqui, pelo modo como pode nos reposicionar quanto a noção de animismo; quanto ao grau de propositividade dos materiais-e-objetos; e quanto ao estatuto hierarquizado homem-matéria, homem-mundo. Em suas palavras:

Uma vez que reconhecemos [homem] nossa imersão [no mundo de matéria], o que este oceano revela para nós não é a homogeneidade branda de diferentes tons de matéria, mas um fluxo no qual materiais dos mais diversos tipos, através de processos de mistura e destilação, de coagulação e dispersão, e de evaporação e precipitação, sofrem contínua geração e transformação. As formas das coisas, longe de terem sido impostas desde fora sobre um substrato inerte, surgem e são suportadas - como, aliás, também o somos - dentro desta corrente de materiais. (Ingold, 2015, p.56-57, grifo nosso)

Sendo homem e matéria não mais que integrantes diferenciados em complexidade, a quebra da hierarquia do homem sobre o objeto é terreno que convida a uma outra relação, uma relação de estar com e não a noção de imprimir desejos e movimentos nos objetos. A meu ver, seus argumentos reposicionam também o animismo, deslocando-o de um caráter transcendental para uma série de acontecimentos existentes na matéria e na conformação objetal. O filósofo francês George Simondon aborda a partir de seu terreno híbrido de pesquisa, uma perspectiva similar. Ele diz: "a matéria viva está longe de ser pura indeterminação ou pura passividade. Tampouco é uma tendência cega; trata-se ao contrário, do veículo de energia informada (Simondon apud Ingold, 2015, p.61). O filósofo menciona não somente a existência desse movimento permanente enquanto energia in-formada (não há passividade), mas aponta ainda para a inexistência de um "modo qualquer" de configuração dessa energia: não há indeterminação, tampouco tendência cega. Isto implica, que cada matéria possui fluxos que a caracterizam enquanto esta e não outra, que a especializa, tal como nos especializa uma certa matéria-homem. A partir dessa perspectiva, escutar a música das coisas é o início de um diálogo para aproximar-se daquilo que a constitui aquilo, relevante sobretudo na linguagem do Teatro de Animação, em que é a matéria, a própria matéria de criação. E talvez seja essa escuta que se relaciona com essa noção 'matérica' de animismo, que interessa a essa pesquisa propor como reflexão: a partir daquilo que o boneco ou objeto tem a dizer, poder pensar o animismo como uma escuta ancorado no movimento que acontece desde as esferas mais íntimas da 
matéria. Uma escuta entre parceiros imersos numa espécie de grande caldo com diferentes tipos de integrantes quanto às suas densidades, organizações moleculares, estruturas, etc., dentre as quais se encontra a matéria de operação complexa de que se constitui homem. Essa perspectiva 'caldolenta', seria uma noção que sustentaria a radicalização da constituição de um plano de imanência, da qual a dramaturgia nasce e se modela, no horizonte artístico aqui apresentado. Plano comum de instauração de diálogo homem-matéria que permite a existência de poesias cênicas como aquela em que "un títere ${ }^{7}$ hecho de hielo que se enamora de una vela encendida. Mientras intenta enamorarla se derrite a su lado. Qué mejor se podría representar al hombre enamorado, de apariencia fría, dura, y que sin embargo se deshace junto a la mujer que ama (Kartun, 2011, p.20). - Uma mostra de um material cênico nascido da sensibilidade às características da matéria.

No que concerne a um objeto, entendido aqui como matéria ou materiais diversos informados (em forma), convocam-se com muito mais força as questões sociais, em seus valores de uso de reconhecimento coletivo. Essa perspectiva afina conexão com o pensamento de criação dramatúrgica no Teatro de Objetos, no qual escutar, se refere não somente à compreensão do permanente movimento de transformação da matéria, mas também a uma escuta que se acentua sobre o sentido coletivo do uso do objeto, quanto ao diálogo com suas características de uso social e às afinações possíveis com outros usos, não sociais, mas cênicos.

O pesquisador francês Jean-Luc Mattéoli constrói uma análise acerca do objeto no Teatro de Objeto numa articulação entre o escrito de Christian Carrignon e um conjunto de reflexões em torno da presença do objeto na Modernidade. Ele vai desenhar um paradoxo acontecido com os processos da industrialização no qual o homem é cada vez mais objetificado, enquanto o objeto vai se humanizando no teatro. Menciona a hiperpresença dos objetos produtos da industrialização que vai mudar os regimes de relação homem-objetos, num processo de aligeiramento, de descartabilidade, acirrado sobretudo pela alienação no processo de produção e pela obsolescência programada. Nesse sentido, o autor aponta uma espécie de reestabelecimento, dentro do Teatro de Objetos, de uma outra relação, opondo-se ao uso aligeirado e desmemoriado do capitalismo. Como se ali o objeto pudesse ter seu espaço, seu tempo, ter uma história, como se ganhasse a importância que lhe fora roubada... Ele vai chamar de "objeto memorial"8 (Carrignon \& Mattéoli, 2009, p.23) o objeto que compõe essa linguagem, afirmando que é "sobre esse fundo de desaparição [...] transfigurado pelo jogo [...] que se erige o teatro e o teatro de objetos pelos quais nós nos interessamos"9 (Carrignon \& Mattéoli, 2009, p.24).

Essa posição importa aqui porque nos remete a refletir acerca de uma noção de memória, ao tempo que toca uma perspectiva política. No que tange a memória, creio que a escuta do artista é fundamental porque, conjuntamente aos aspectos da fisicalidade do material, os usos sociais e os aspectos simbólicos coletivos serão

\footnotetext{
${ }^{7}$ Para esse texto, o termo títere equivale a marionete, que equivale a teatro de animação. Essa escolha deve-se ao fato de que na maioria dos países de língua castelhana, o termo Teatro de Títeres é usado para dar conta de todas as linguagens que no Brasil chamamos de Teatro de Animação e na França, Théâtre de Marionnette: Teatro de Bonecos, Teatro de Objetos, Teatro de Sombras e Teatro de Máscaras.

8 L'objet mémoriel

${ }^{9}$ Sur ce fond de disparition transfiguré par le jeu que s'enlèvent le théâtre et les objets auxquels nous nous intéressons. (Tradução nossa).
} 
franco material de pesquisa de composição. Isto implica que mesmo que o tema da memória não seja a questões central em um determinado projeto artístico, o caráter funcional e simbólico cultural imbricado no objeto não pode ser relevado, sob o risco da total perda do referencial de comunicação na estrutura dramatúrgica, referencial necessário mesmo para subverter as próprias referências. Nessa direção, a memória comunal advém um dado dramatúrgico. Nas palavras de Justine Duval (2012, online):

Extraído do real, esse tipo de objeto é portador de memória coletiva e pessoal muito forte. Ele é carregado imediatamente. Ele vai, assim, evocar lembranças pessoais $[\ldots]$ ou convocar elementos compartilhados por todos: uma publicidade conhecida, um período histórico determinado ou ainda uma conotação ancorada no inconsciente coletivo. Porque ele é reconhecível por todo mundo, o objeto fala de nós. ${ }^{10}$

Na criação O Retorno a Juberlano, a memória e o sentido político de recuperação aparecem como um dos primeiros parâmetros de criação. O projeto se desenha a partir do desejo do Grupo Ânima em dialogar com o artista plástico cearense Chico da Silva. Chico criou em suas pinturas, criaturas fantásticas, oriundas de um lugar que ele nomeava Juberlano. A proposta dos artistas era constituir cenicamente o retorno a esse Juberlano, reinventando-o no mesmo movimento. Para tanto, propuseram-se uma imersão investigativa no contexto onde vivia Chico na sua última "fase" da vida. Esse lugar chama-se hoje bairro Pirambu e é uma zona praieira, nutrida de toda a ambiência cultural emergida entre o processo de urbanização e as atividades pesqueiras e seus modos de vidas constituídos em torno dessa atividade. Desse universo, os artistas optaram por trabalhar com o que chamaram de objetos-dejetos: objetos descartados pela perda da sua utilidade. Os artistas realizaram uma cartografia desses objetos a partir do estabelecimento de múltiplos encontros com o espaço, a fim de elencar um conjunto de objetos que seriam estabelecidos como ponto de partida para a sua pesquisa da linguagem do Teatro de Objetos. Nesse movimento cartográfico encontraram um "cemitério de objetos" vinculados a pesca artesanal, no qual os objetos 'desistidos' eram deixados, disponíveis para possibilidades de reutilização por outrem. Um gesto que parece escutar a voz de Brecht aconselhando desde 1936, a buscar os objetos do teatro num 'canteiro de demolição' ou conversar com Tadeusz Kantor que "em 25 anos de intervalo usa [...] aproximadamente a mesma fórmula: numa situação de urgência e de escassez provocada pela História, ele [...] se agarra [...] ao objeto deteriorado ou quebrado que ele [...] tem "à mão" e lhe promove [...] a posição de obra de arte"11 (Carrignon \& Mattéoli, 2009, p. 21).

\footnotetext{
${ }^{10}$ Extrait du réel, ce type d'objet est porteur d'une mémoire collective et personnelle très forte. II en est chargé d'emblée. II va ainsi évoquer des souvenirs personnels [...] ou convoquer des éléments partagés par tous : une publicité connue, une période historique déterminée ou encore une connotation ancrée dans l'inconscient collectif. Parce qu'il est reconnaissable par tout le monde, l'objet parle de nous. (Tradução nossa)

11 à vingt-cinq ans d'intervalle, usent à peu près de la même formule: dans une situation d'urgence et de dénuement provoquée par l'Histoire, ils se saisissent de l'objet abîmé ou cassé qu'ils ont "sous la main" et le promeuvent au rang d'œuvre d'art. (Tradução no singular porque no original havia referência conjunta a Kurt Schwitters). (Tradução nossa).
} 


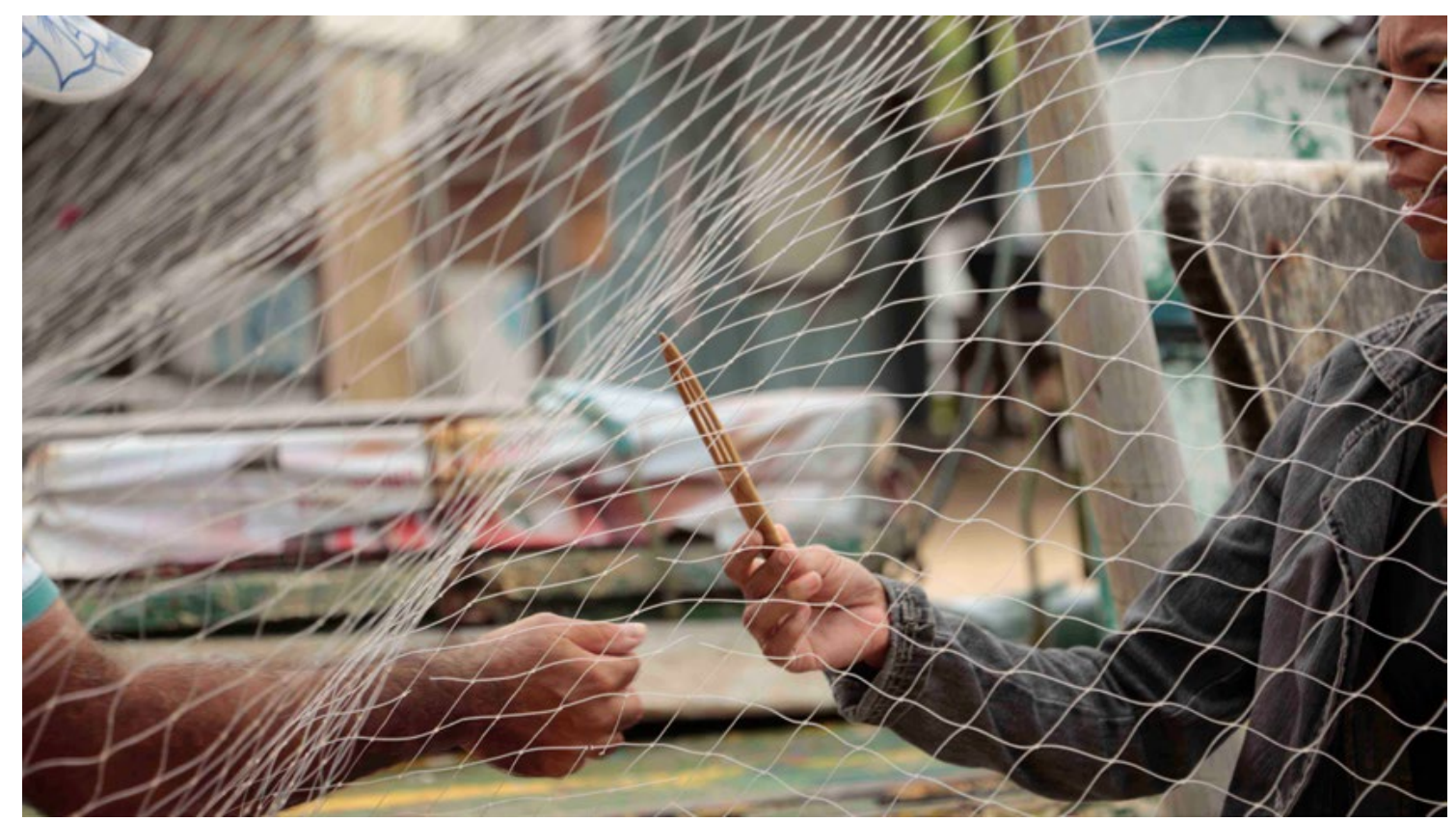

Cartografia no bairro Pirambu. Na imagem, a atriz Tatiane Souza com um pescador. Foto: Cleomir Alencar. Fonte: arquivo pessoal

Dramaturgicamente, pensar o objeto com um olhar para suas memórias pode se dar de um modo mais ou menos acentuado. A composição poderá ter como orientação primeira um desejo mais explícito de trabalhar as memórias de alguém ou as memórias de guerra, por exemplo, com gestos dramatúrgicos intencionais de acesso a um momento histórico. Noutro sentido, essa perspectiva memorial pode não tomar relevo, constituindo outros movimentos dramatúrgicos, mantendo outro diálogo com a memória, qual seja a criação de um plano comum de sentido sobre o qual se estabelece o espetáculo. Na Juberlano do Grupo Ânima, segundo a atriz-criadora Tatiane Sousa, a pesquisa apoia-se "no uso de Objetos, proposto por Tadeusz Kantor, no qual desconstrói-se sua semântica utilitária e instaura-se uma outra gama de signos, considerando-se sobretudo a memória que lhe foi impressa pelo tempo de uso" (Ânima, 2017, no prelo). Acerca do tema, numa conversa pública ocorrida no transcurso do projeto com Sandra Vargas e Luiz André Cherubini ${ }^{12}$, refletimos sobre o apoio na semântica utilitária para escrita cênica. Esse momento provocou reflexões sobre como o uso dos signos utilitários, pode ser afirmador também das regras propostas ou impostas pela indústria, uma vez que, de modo geral, quase não temos em nossas mãos objetos artesanais. Assim, o processo de reinvenção semântica pode constituir também um pequeno gesto de resistência, quando viabiliza ao objeto encontrar outras "vidas". Perspectiva que faço dialogar com o que Christian Carrignon vai chamar de máquina de escrever, no qual o ator recarrega poeticamente o sentido do objeto, realizado nesse gesto de diálogo, em que cada objeto "[...] tem o mesmo efeito que uma restrição forte para um escritor, não partimos da página branca. Quando interrogamos um objeto, [ele] tem sempre algo a contar [...]"13 (Carrignon, 2009, p.32).

\footnotetext{
12 Sandra e André são os criadores e diretores do Grupo Sobrevento, de São Paulo. Ela tem trabalhado na curadoria de festivais especializados em Teatro de Objetos e esteve conosco ministrando oficina para o grupo. Num enorme gesto de generosidade, esteve também presente nessa palestra, juntamente com André, ambos compartilhando reflexões acerca do tema.

${ }^{13}[\ldots]$ les mêmes effets qu'une contrainte forte pour un écrivain, on ne part pas de la page blanche. Quand on interroge un objet, il a toujours quelque chose à raconter [...]. (Tradução nossa)
} 
Gosto dessa perspectiva de Carrignon de pensar os objetos como máquinas de escrever poesia. Ao ator cabe escutar suas histórias: suas possibilidades físicas e funcionais, bem como perscrutar suas simbologias sociais, num gesto considerado aqui como basilar, ainda que seja pelo gesto de afastamento dessas referências, para a composição dramatúrgica no Teatro de Objetos.

\section{Estruturas Dramatúrgicas}

\section{Elementos de linguagem}

O pesquisador francês Didier Plassard (2012), aponta o surgimento do Teatro de Objetos como um braço do Teatro de Animação, emergido no início dos anos 1980, mas vai sublinhar a existência de algumas experiências como relevantes e preexistentes a esse momento em que a linguagem se efetiva. Ele lembra o artista israelense de origem inglesa Dennis Silk, que nomeia seu teatro de "Teatro das Coisas" e menciona também o artista Stuart Sherman, com performances que começam desde a metade dos anos de 1970. No campo das artes visuais, vai sublinhar experiências ocorridas bastante antes: Paul Klee, com Fantôme électrique ou Spectre de la boîte d'allumettes, entre 1916 e 1924, onde a cabeça do fantasma é uma tomada elétrica e o espectro uma junção de caixas de fósforos, coloridas e com dois olhos pintados. Plassard menciona Pablo Picasso, que em 1942 constrói uma escultura com cela e guidão de bicicleta, a Tête de Taureau. O pesquisador coloca em relevo também as experiências dos cabarés parisienses que, em 1950, já desviavam o uso dos objetos e materiais para fins marionéticos: Yves Joly, com Une tragédie de papier, Ombrelle et parapluies ${ }^{14}$, ou ainda George Tournaire, com Cravate Circus. Como pesquisadora, dentro do pequeno âmbito documental que tive acesso, seriam eles os primeiros a realizarem, na França, a linguagem do Teatro de Objetos, com a utilização não apenas de objetos, mas também partes do corpo e materiais animados como personagens ${ }^{15}$. Yves Joly, inclusive, inseria ali o Teatro de Matéria, com seus papéis pintados, numa performatividade distinta da que realiza, por exemplo, o Teatro de Matéria de Simon Moers, em Sous la neige qui tombe ${ }^{16}$ (de 2010), no qual o artista faz uso de sementes e areia para contar uma lenda chinesa, sem fazer uso de adaptação dos materiais.

Em todos os contextos mencionados, mesmo no âmbito das artes visuais escultóricas, se evidência um dos princípios considerados por muitos pesquisadores-artistas um fundamento do Teatro de Objetos, qual seja o deslocamento do objeto ou matéria de seu uso ou contexto cotidiano em prol da constituição dramatúrgica baseada na produção de uma dupla visão: uma, calcada no seu uso inserido na vida, em seu contexto social, e outra, vinculada à camada concernente ao uso poético engendrado na cena. Trata-se de um deslocamento do sentido utilitário para elaboração de um outro, poético. Nessa linguagem, o uso do objeto dialoga com a noção

\footnotetext{
${ }^{14}$ Didier Plassard atribuiu Ombrelle et parapluies ao artista George Lafaie. No entanto o pesquisador Henryk Jurkowski, em seu livro Métamorphoses: La marionnette au XX siècle. Atribui a Yves Joly, o que também ocorre no site de Portal das Artes da Marionete. Aqui mantive a perspectiva de Jurkowski.

${ }^{15}$ Não foram eles, entretanto, que nomearam esse território como Teatro de Objeto, nem estabeleceram esse terreno como campo de pesquisa específico. 0 que fizeram as companhias Théâtre de Cuisine, Vélo Théâtre e Théâtre Manarf, em março de 1980.

${ }^{16}$ É possivel ver um pequeno trecho no site do Portal da Marionete em https://www.artsdelamarionnette.eu/audiovisuel/sous-la-neige-qui-tombe-solo-de-simon-moers-a-lesnam/
} 
de ready-made, ao incorporar o objeto na criação sem que haja uma elaboração prévia para o trabalho, contrariamente ao que ocorre com o boneco que é construído com o propósito cênico. Nessa perspectiva, o artista Christian Carrignon sublinha o papel de poeta que cabe ao ator na construção cênica do sentido do objeto. Para ele, o ator deve "carregar" emocionalmente o objeto com "[...] falsas lembranças, falsas histórias, falsas emoções: nós estamos no teatro! O objeto falsamente pessoal é uma caixa de inventar sonhos"17 (2009, p. 31-32). Enquanto nas demais linguagens do Teatro de Animação a personagem carrega muito de si desde o planejamento da sua construção, no Teatro de Objetos o ator deve realizar escolhas de significação a partir do objeto dado: "carregar o objeto significa que o objeto põe em carga uma parte do discurso pela intenção que projeta sobre ele o ator"19, aponta Justine Duval, do que, em sua concepção coloca o ator como elemento central da linguagem e que, ademais, "contrariamente a certos espetáculos de marionetes onde o manipulador pode "desaparecer", o Teatro de Objetos afirma fortemente a presença do ator."19 (2012). Tais afirmações, oferecem elementos para continuar a pensar termos constitutivos dessa linguagem. As premissas de Justine tocam o possível caráter de acirramento da centralidade do ator com relação a outros campos do Teatro de Animação. Decorre dessa perspectiva, a acentuação do papel de implicação na criação dramatúrgica por parte do ator: o objeto, ante seu sentido social-utilitário, deve ganhar novo sentido pelo trabalho do ator, dificilmente se dando pelo primado textual, mas de fato acontecendo pela pesquisa do ator. Ou seja, mesmo que haja um texto ou narrativa prévia sobre a qual criar, é somente no trabalho do ator que se estabelece como e quais objetos conseguem ganhar sentido naquele contexto diegésico. Caso não hajam narrativas prévias, é também o ator que vai construir dramaturgia a partir das escolhas dos objetos e constituição dos sentidos atribuídos. Esse processo aproxima-se do que Carrignon nomeia poeticamente de palimpsesto, palavra que se refere a papiro ou pergaminhos, que tinham seus textos raspados para permitir outra escritura. $O$ ator, portanto, vai compor com o objeto dinâmicas que o particularizam para aquele trabalho, em diálogo com a carga de sentido comum - social e matérica - que ele já carrega, reescrevendo seu uso, agora cênico, na produção de sentido.

A composição dessa dinâmica de ressignificação traz ainda uma particularidade desse gênero marionético, qual seja um acirramento dos processos de metaforização e metonimização. No Teatro de Objetos, a dramaturgia ocupa-se mais em evocar, apontar, sugerir que representar. Nesse processo, faz-se necessário estabelecer um campo de constituição do código, um plano comum entre artista e espectador, de reconhecimento do sentido atribuído ao objeto em seu processo de deslocamento do uso 'doméstico' para o uso cênico. Processo acerca do qual o artista Simon Moers diz "aliás[,] que a maior parte [...] [de seu] espetáculo consiste em instalar códigos a fim de que as matérias façam sentido para o espectador"20 (apud Duval, 2012, online).

\footnotetext{
17 [...] faux souvenirs, de fausses histoires, de fausses émotions: nous sommes au théâtre! L'objet faussement personnel est une boîte à s'inventer des rêves. (Tradução nossa)

${ }^{18}$ Charger l'objet signifie que l'objet prend en charge une partie du discours par l'intention que projette sur lui le comédien. (Tradução nossa)

19 Contrairement à certains spectacles de marionnettes où le manipulateur peut "disparaître", le Théâtre d'objet affirme fortement la présence de l'interprète. (Tradução nossa)

${ }^{20}$ [...] d'ailleurs que la majeure partie de ce spectacle consiste à installer des codes afin que les matières fassent sens pour le spectateur. (Tradução nossa)
} 
O tamanho do objeto e o uso do espaço também constituem elementos de orientação dramatúrgica. Christian Carrignon, em seus escritos, usa frases em seus textos, tais como: "espetáculos de mesas", "O primeiro mecanismo reparado do teatro de objetos é a mudança de escalas [...]", "[...] um utensílio de cozinha, ou um bibelô são feitos para seres sonhados na palma da mão.", "E se de seu lugar, os espectadores não distinguem os detalhes do objeto, sua própria experiência o constitui em sua integridade"21 (2009, p.25-29-27). Essas expressões indicam o trabalho com objetos de menor dimensão física, dado constitutivo de movimentos compositivos específicos para o trabalho do ator e sua relação espacial, traçando outras texturas dramatúrgicas. O artista sublinha ainda, com relação a dimensão física do objeto, uma ancoragem na dimensão da memória afetiva que ele carrega: o objeto contém um "tamanho afetivo [...] maior que seu tamanho real. ${ }^{22 " ~(2009, ~ p .27) . ~ E ~ a q u i ~ a p a r e c e ~ u m a ~ r e l a c ̧ a ̃ o ~ n a ~}$ qual o aspecto de memória afetiva-coletiva possibilita a escritura dramatúrgica com objetos que não propiciam uma completa visibilidade para o espectador, conectando novamente a questão da memória como matéria dramatúrgica.

Em Juberlano, o grupo começa a pesquisa a partir de objetos memoriosos, que me chamavam atenção pelos seus tamanhos maiores que o humano ou de grande peso, 0 que me colocava já ali, uma questão, referente ao trabalho do ator e, outra, de ordem dramatúrgica. Rede de pesca, a base de uma fateixa, samburá e cordas, afastavam o trabalho de mesa como previsão, instaurando um ambiente marionético imersivo. Diferente de ter diante de si uma mesa com objetos pequenos, esses objetos grandes convocavam um trabalho corporal de maior amplitude espacial, já tracejando certos convites dramatúrgicos e certas perspectivas performativas do ator. Não menos importante e tão integrante desse plano compositivo, estavam os pequenos objetos coletados: agulhas para rede de pesca, pequeno pote de cerâmica, sinos, cachimbo, conchinhas. Esses objetos vão convocar uma lida corporal e dramatúrgica que estabeleça esse diálogo de dimensões, encontrando a afinação justa, uma vez que, carregar o pesado e o leve na mesma mão pode ser bem mais difícil que carregar somente um ou outro.

\section{Terrenos dramatúrgicos}

O jogo de criação de sentido para o objeto se estabelece através de diferentes caminhos, sendo um deles o trabalho do ator (complementação da personagem-objeto, duplo da personagem-objeto, ator-contador, à vista, oculto); e outro deles, percorre alguns modos de estruturações dramatúrgicas basilares (antropo-zoomorfia; narrativo, visual). Estes últimos, estabelecem pelo menos três grandes terrenos dramatúrgicos no Teatro de Objetos.

No exercício da minha função de acompanhamento de criação do grupo Ânima, colocava-se para mim, a tarefa de entender para qual grande terreno dramatúrgico desejavam partir. Entre um Teatro de Matéria e Teatro de Objeto, o primeiro havia se distanciado, inicialmente, pelas próprias intenções de trabalhar com os objetos-

\footnotetext{
${ }^{21}$ Spectacles de table" (p. 25); "Le premier mécanisme repéré du théâtre d'objet est le changement d'échelle [...]" (p. 29); "(...) un ustensile de cuisine, ou un bibelot sont faits pour être rêves au creux de la main." (p.27); "Et si de leur place, les spectateurs ne distinguent pas les détails de l'object, leur propre expérience le reconstitue dans son intégrité." (p. 27). (Tradução e grifos nossos)

${ }^{22}$ Leur taille affective [...] plus grande que leur taille réelle. (Tradução nossa)
} 
-dejetos já colhidos em processos cartográficos nas múltiplas visitações ao bairro Pirambu. Nesse âmbito, um primeiro terreno poderia seria vincular-se ao movimento de antropo-zoomorfização dos objetos.

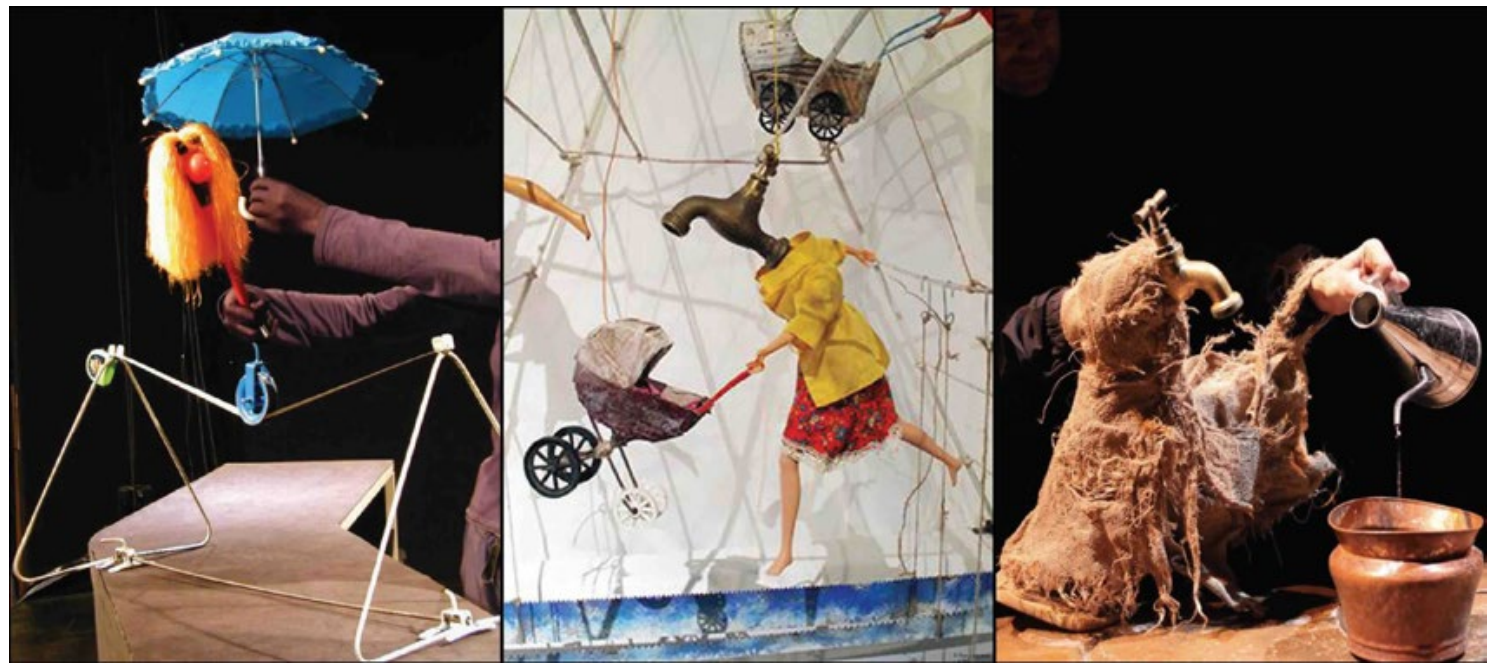

Personagens Antropo-zoomorfas no Teatro de Objetos. Da esquerda para a direita: Espetáculo O Circo dos Objetos, direção de Mariza Basso; Instalação L'appartement témoin, de Michel Laubu; Espetáculo L'Avare, Cia Tábola Rassa ${ }^{23}$

Nesse contexto, os objetos encontrados sofreriam uma espécie de assemblagem permanente ou no momento da cena, pelo gesto do ator, -para constituir uma personagem que remete ao humano ou animal.

Uma vez que o universo pictórico do artista Chico da Silva é produtor de um universo fantástico de criaturas inventadas, essa composição de figuras cênicas poderia ser um mobilizador de partes ou totalidade dramatúrgica do trabalho. Plassard, menciona graus de reelaboração do objeto, dentre os quais figura a criação de uma "quase-marionete", tornando o estabelecimento do código para o espectador de imediato reconhecimento. Nesse sentido, ele menciona Michel Laubu e no Brasil poderíamos mencionar Marisa Basso em O Circo dos Objetos, por exemplo.

No primeiro caso, referente a imagem do meio, o uso da "quase-marionete" insere-se num ambiente instalativo, entre artes cênicas e artes visuais, num contexto dramatúrgico que se distingue do uso cênico. No segundo exemplo, relativo à imagem mais à esquerda, do $O$ Circo dos Objetos, se estabelece o uso cênico, colocando outras questões. Em geral, a inserção da antropo-zoomorfia na cena acentua o trabalho do ator em torno da animação, no sentido de "dar vida" à personagem, do que decorre uma ênfase no uso do procedimento cinético enquanto partituras de ação e gestualidades como base do processo de criação da personagem. Numa certa medida, esse território de operação do Teatro de Objetos o coloca muito mais próximo de uma marionete que das características que vem se delineando como sua especificidade. Esse processo, é ainda distinto do modo de antro-zoomorfização que pode ser visto na companhia Tabola Rassa, que coloca em cena $O$ Avarento ${ }^{24}$, de Molière, utilizando uma multiplicidade de torneiras com pedaços de tecidos que constituem corpo da personagem, juntamente com as mãos dos atores. Nesse espetáculo, estruturado

\footnotetext{
${ }^{23}$ Fonte: Disponivel em: <http://marizabasso.com.br/o-circo-dos-objetos/> Acesso em: 30 maio 2018; Disponivel em: <http://www.museedesconfluences.fr/fr/ evenements/appartement-témoin> Acesso em: 30 maio 2018; Disponivel em: < http://www.tabolarassa.com/l-avare.html > Acesso em: 30 maio 2018.

${ }^{24}$ Você pode ver um vídeo acerca da composição das personagens em: https://www.youtube.com/watch?v=AYMEsTraOJ8
} 
numa dramaturgia ancorada no texto clássico de Molière, as camadas de sentido produzidas com o objeto são mais presente, estabelecida no jogo das torneiras entre a economia/acúmulo de água e a economia/acúmulo monetário humano. Assim, dentro ainda do modelo de antropo-zoomorfização dos objetos, podemos pensar a partir de diferentes níveis de interferência de modificação do objeto, bem como distintas estruturas dramatúrgicas possíveis. Nos exemplos mencionados, enquanto o trabalho de Michel Abu estabelece uma estrutura dramatúrgica cênico-instalativa; o trabalho $O$ Circo dos Objetos, baseia-se numa estrutura de um recorrido de esquetes fechadas em si; e $O$ Avarento, estabelece estruturação de um texto teatral clássico, num processo dramatúrgico não fragmentado.

Em Juberlano, de todos os caminhos possíveis para a pesquisa de invenção cênica, o grupo instaurou como premissa a NÃO antropo-zoomorfização, apontando uma pesquisa calcada na não modificação no objeto, do que apenas sabíamos tratar-se de um trabalho que não caberia numa mesa e tomava uma dimensão de ocupação espacial mais ampla. Por conseguinte, faziam-se possibilidade os outros dois terrenos dramatúrgicos: um que se articula em torno do uso da narrativa e outro, que se articula na produção de uma dramaturgia cinético-visual.

Quando a estrutura narrativa é base de uma construção dramatúrgica, um movimento bastante encontrado no Teatro de Objetos é aquele que se assemelha ao contador de histórias. Nele o objeto pode ou não ganhar uma sutil sugestão antropo-zoomorfa, mas isto, caso ocorra, se dá não pela forma de assemblagem dos objetos, mas por partituras de movimento que aparecem e desaparecem na mesma mecânica do duplo jogo com os sentidos ordinários e poéticos do objeto, demarcando um jogo dramatúrgico mais de menção que de representação. É o caso do icônico Petits suicides de Gyula Molnàr (1984) ${ }^{25}$, no qual se estabelece uma composição com bombons, um copo d'água e um medicamento efervescente. Nesse sentido, a manipulação do objeto pode assumir aquilo que mencionou Jean-Luc Mattéoli, citado por Plassard (2012): uma espécie de "grau zero" de manipulação, fruto, a meu ver, do acento da linguagem sobre a produção de indicativos, de menções, mais que apresentação de personagens e sequencias accionais. Assim, tem-se o afastamento do procedimento de animação no sentido cinético e se estabelece um trabalho de produção de sentido que se instaura pela articulação entre palavra ${ }^{26}$ e manipulação "grau zero". Essa manipulação "grau zero" acontece muitas vezes apenas com o olhar focal para o objeto, ou deslocamentos do objeto de um lugar a outro da cena, ou um gesto quase único do ator, como pintar ou quebrar o objeto, na produção metafórica ou metonímica. Didier Plassard (2012, p. 3) vai dizer que, "muito mais que a manipulação efetiva, é frequentemente a palavra que entra em jogo: pelo seu poder apenas, o objeto pode devir outra coisa que esse utensílio ordinário que nós nem mesmo percebemos mais"27. Fazendo uso do jogo lúdico com a palavra, ela toma centro desse processo de metamorfose do entorno cênico, motivo pelo qual o autor vai mencionar a existência

\footnotetext{
${ }^{25}$ é possível ver uma versão desse trabalho com atuação de Christian Carrignon em: https://www.youtube.com/watch?v=d2chORT7ig4\&t=2s

${ }^{26}$ O termo aqui, implica também gramelôs, onomatopéias e outros sons.

${ }_{27}$ Beaucoup plus que la manipulation effective, c'est souvent la parole qui entre en jeu : par son seul pouvoir, l'objet peut devenir autre chose que cet ustensile ordinaire que nous ne remarquons même plus. (Tradução nossa)
} 
de manipulação no Teatro de Objetos, atribuindo-lhe, entretanto, um caráter mais mental que físico, assumindo função de apresentação e não, de animação. Nesse âmbito, o ator afina sua presença cênica podendo também "apagar-se", ou estabelecer uma função de motor da maquinaria cênica, assim como pode interpretar uma personagem, ser um duplo da personagem-objeto, ser complementar a ela ou pode devir corpo-cenário, em geral, realizando o trânsito entre essas distintas presenças, de modo abrupto, sem muitas cerimônias.

O ator-contador do Teatro de Objetos atua muitas vezes por onomatopeias e mesmo sem palavras, sempre nesse trânsito possível de variações da afinação da presença cênica, como podemos ver no trecho do espetáculo Le Polichineur de Tiroirs, Cie Les Chemins de Terre ${ }^{28}$. Essa perspectiva do predomínio do estruturas narrativas como base desse terreno dramatúrgico, é afirmada na concepção de Carrignon, quando diz que "o objeto está sempre pronto a retomar sua potência de evocação quando o colocamos em conexão com uma narrativa, verbal ou muda"29 (Carrignon apud Duval, 2012, online, grifo meu). Assim, estamos tateando num terreno que, prescindido mais ou menos da palavra, e variando os diferentes modos de estar em cena, desenha-se como um terreno dramatúrgico que opera, em geral, com narrativas, em formato de esquetes ou estendido.

Essas considerações conversam com algumas reflexões de Didier Plassard, sobre dramaturgia no Teatro de Animação. Em suas palavras (2012, online):

$\mathrm{O}$ teatro de marionetes e o teatro de objetos tem belos sucessos sobre o plano visual e plástico, mas ele se recusa demasiado frequentemente a tomar em conta a dimensão da dramaturgia. Essa falta de dramaturgia se faz notável em pelo menos dois planos: de uma parte, a construção da narrativa pena a devir um pouco mais ambiciosa que a forma breve; de outra parte, a relação ao repertório ou mais amplamente ao texto pena em se estabelecer cenicamente. ${ }^{30}$

Essas questões dialogam com o terceiro terreno dramatúrgico a ser tocado no presente artigo e que foi aquele que mobilizou a pesquisa realizada pelo Grupo Ânima. Iniciando pela compreensão do termo dramaturgia, estabelecemos caminhar a partir da concepção da dança. A dança comporta um desenho de fluxos compositivos alinhados com uma produção de sentido muito mais vinculada a instalação de uma produção sensorial, imagética, de discurso lacunar que com a eloquência discursiva. Sem desejar estabelecer um sentido enrijecido, essa linguagem vem desenhando algumas perspectivas para a compreensão do termo dramaturgia, que nessa pesquisa, conversa com a carta de doutorado que Rosa Hércoles escreve a Pina Bausch (2005, p. 112):

Não sei se você concordaria comigo, mas proponho que entender a dramaturgia de uma peça coreográfica implica na identificação de que tipo de pensamento está sendo implementado tanto no corpo quanto no ambiente cênico, observando-se quais as relações que foram estabelecidas entre seus materiais constitutivos. Entendo que, em sua obra, esta construção se dá pela não-linearidade dos fatos,

\footnotetext{
${ }^{28}$ Pode ser acessado em: https://www.youtube.com/watch?v=AyZ6MLfPg7M

29 [L'objet] est toujours prêt à reprendre sa puissance d'évocation quand on le met en connexion avec [un] récit, verbal ou muet.

${ }^{30}$ Le théâtre de marionnettes et le théâtre d'objets ont de belles réussites sur le plan visuel et plastique, mais ils se refusent trop souvent à prendre en compte la dimension de la dramaturgie. Ce manque de dramaturgie se remarque au moins sur deux plans : d'une part, la construction du récit peine à devenir un peu plus ambitieuse que la forme brève ; d'autre part, la relation au répertoire ou plus largement au texte peine à se mettre en place. (Tradução nossa)
} 
pelo cruzamento de diferentes domínios estéticos para reposicionar suas materialidades em tempos e espaços distintos. Uma dramaturgia que sobrepõe, contrapõe, associa, distorce e redimensiona as relações de corpo e lugar, criando uma textura cênica que projeta realidades paralelas.

Essa noção vincula-se ao que Silvia Soter (2014, p. 34) vai chamar de escrita em uma peça de dança, gesto que trata da "articulação e a ênfase atribuída aos distintos elementos da cena". Frequentemente a dança contemporânea se propõe uma questão, tema ou conceito para investigar. Para mim, sua força está justamente em como ela se autoriza a situar-se deslocada de uma produção de sentido cognoscível no âmbito da racionalidade, para avançar em outros modos de diálogo e pensamento, que passam e tocam também o terreno dos sentidos do corpo e das sensações. Ela comporta, a dança, uma dramaturgia que aposta mais na produção de texturas de sentido que na eloquência discursiva (nos termos tradicionais), encontrando aí um modo mesmo de produção de pensamento.

Essa premissa mais aberta do conceito de dramaturgia, entretanto, não se restringe ao universo da dança, tão pouco nasce ontem no campo teatral. Se pensarmos em Samuel Beckett, por exemplo, ou em todos os criadores vinculados ao teatro pós-dramático, sobretudo nos dias atuais, encontraremos uma multiplicidade de dramaturgias que radicalizaram e reinventaram em diferentes níveis a ruptura narrativa. Ante o exposto, a afirmação de Plassard me provoca reflexões acerca de uma espécie de hierarquização de validação acerca do que ele regimenta como teatro: teria mesmo o Teatro de Animação que produzir nos terrenos mais amplamente conhecidos do Teatro para falarmos da existência de dramaturgia? Não seria a renovação do Teatro de Animação, ocorrida a partir do século XX, a criação de premissas dramatúrgicas específicas ao fazer dessa linguagem? Não seria interessante, tal como a dança o fez, investigar que dramaturgias constituem esse campo artístico? O encontro com o pensamento de dramaturgia da dança (ou teatro pós-dramático), realoca, nesta pesquisa, a noção de inadequação do Teatro de Animação no sentido de que o "texto pena em se estabelecer cenicamente", deslocando-a para a noção de diferenciação dramatúrgica. Minhas intuições aportam numa noção de pesquisa dramatúrgica que pensa o Teatro de Animação a partir de outras potencialidades quanto ao teatro. Reflexão presente nas palavras de Maurício Kartun (2011, p. 19), dramaturgo do Teatro de Animação, quando nos diz que "o títere nos permite trabalhar com uma matéria capaz de realizar o que para o ator é impossível. $O$ fascinante da dramaturgia para títeres é o desafio de trabalhar sobre o ilimitado da matéria como elemento expressivo"31. Essa perspectiva reverbera aqui no sentido de olhar para as especificidades dessa linguagem a fim de encontrar sua força compositiva, vista não como fragilidade, concepção emergida de uma possível hierarquização relativa aos cânones teatrais, aqui tensionada, ademais, pelo pensamento dramatúrgico da dança que, não se instala pelo texto, mas por outros modos de produção de sentido.

Partindo dessa compreensão mais aberta de dramaturgia, me posiciono ao lado do Grupo Ânima, tateando possibilidades compositivas a partir dos materiais recolhidos e escolhidos por cada ator. Peso, textura, uso ordinário, carga simbólica, eram

31 el títere nos permite trabajar con una materia capaz de realizar lo que para el actor es imposible. Lo fascinante de la dramaturgia para títeres es el desafío de trabajar sobre lo ilimitado de la materia como elemento expresivo. (Tradução nossa) 
elementos tomados em conta num processo de pesquisa que podia ser guiado desde a pesquisa ancorada na fisicalidade da relação entre corpo e objeto, até procedimentos de criação de metáforas. De um modo, de outro ou misto, o grupo foi levantando um material extremamente físico e visual, buscando entender e ajustar no caminho procedimentos afastados do primado textual ou narrativo para a pesquisa.

A partir de cenas criadas, realizávamos um trabalho de texturização, que consiste em cuidar da realização dos gestos, dos deslocamentos e de encontrar a justa relação entre o objeto portado e as intenções cênicas desejadas. Esse processo comportava muita experimentação: normalmente o cuidado com a textura cênica faz emergir novas possibilidades de desdobramento. Noutro movimento, empenhamos tempo em estudar ideias que surgiram a partir da relação de um objeto específico com o espaço de ensaio, como por exemplo, as cordas. Esse objeto tão presente no fazer do pescador, produzira na pesquisa o desejo de ganhar o plano mais alto do espaço físico. Abrindo essa investigação, os atores, mais uma vez voltam e escutar as distintas dimensões do objeto em busca de criação de cena, estabelecendo vários jogos cênicos entre eles, as cordas e as estruturas de sustentação da sala de ensaio. A rede que antes ficara no chão experimenta suspensão, bem como a fateixa e os próprios atores. O trabalho ganha ainda mais tridimensionalidade espacial e questiona os sentidos instaurados pelo material preexistente, movimento natural nesse modelo de criação dramatúrgica.

Com um conjunto de cenas à mão e data de mostra de processo prevista, emerge a tarefa de experimentar como articular esses materiais, convidando certas ações compositivas para a criação dramatúrgica: juntar, justapor, contrapor, acrescentar, cortar, dilatar, recolher. No exercício de interlocução poética em dança, 'criei' alguns dispositivos que pareciam caber no contexto da pesquisa, um deles, relativo a elaboração de roteiros. Trata-se de, a partir de um mapa rizomático de fragmentos cênicos levantados, estabelecer algumas sequencias possíveis. Esses roteiros podem ser desenhados a partir de diferentes parâmetros criados. No caso, tomamos como premissa uma espécie de subtexto extraído das cenas criadas e, também elencamos a premissa rítmica como parâmetro. Ainda nesse sentido, os pesquisadores elegeram um fluxo fluído de transições, constituindo um outro parâmetro dramatúrgico. É válido sublinhar esse movimento dramatúrgico no qual uma espécie de sentido em forma de subtexto vai emergindo a posteriori ou junto da pesquisa de criação de cenas e não necessariamente antes, e no qual outros fatores, como ritmo podem ganhar importância compositiva. Creio ser esse um movimento muito possível dentro do Teatro de Animação, Teatros Físicos e Teatros Visuais, Dança-Teatro, Dramaturgia Circense, que contam com a materialidade dos objetos, dos corpos, dos equipamentos, do movimento e da visualidade como fatores preponderantes na criação e realização de cenas. 


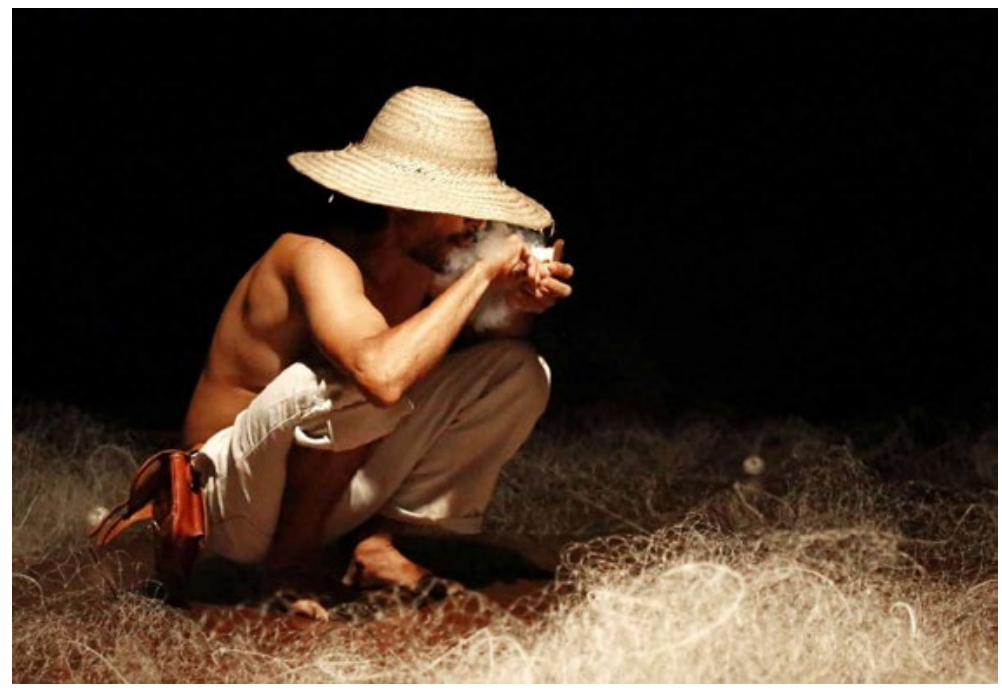

O Retorno a Juberlano. Em cena, o ator Cleomir Alencar

Foto: Joyce Vidal. Fonte: arquivo pessoal

Com esse Teatro de Objetos instalado, ou seja, ocupando amplo espaço, e, com o estabelecimento de uma pesquisa dramatúrgica no terreno físico-visual, todos os elementos que evolvem o fazer cênico tomam relevo compositivo: pensar desde o processo, a luz, a localização a plateia, a saída de atores e uso lateral do espaço ou não, dentre outras questões. Esse movimento era acompanhado de uma ideia que defendo bastante no processo de criação dramatúrgica, de ir apresentando o processo do trabalho em busca da tessitura de um entendimento desta, que se configura de outro modo quando na presença do público. O Grupo Ânima experimentou diferentes modos de estar em cena no que se refere à localização da plateia, ao uso da luz, às saídas do palco, ao passo que ia experimentando os roteiros estabelecidos. Num movimento dialético, esse roteiro escolhido temporariamente, era também o campo sobre o qual se experimentava realizar a texturização, mas agora não apenas de uma cena e outra, mas uma texturização da composição dramatúrgica geral do trabalho. Inicialmente com uma 'monocromia' rítmica, buscamos entender uma espécie de gráfico de energia, tentando fortalecer e jogar com as energias mais altas com relação às mais amenas. Bem como é aqui que os trabalhos de decisão de realização de justaposição, expansão, recolha, corte ou acréscimo tomam centralidade.

Assim, o grupo desenhou um espetáculo cênico "longa-forma" e uma pesquisa em torno desse que, chamei de terceiro grande terreno dramatúrgico e que se estabelece a partir da ênfase acerca dos aspectos físicos-visuais na criação. Esse processo gera uma produção de sentido mais aberta à atividade do espectador. Numa certa medida, ser arrastada dentro de uma rede de pesca (cena de O Retorno a Juberlano), fala sobre as prisões a que estamos submetidos, cada um de nós, espectador. No entanto, aquilo que nos aprisiona, é para cada um, algo que dialoga com seu modo de existir, instaurando uma obra de sentido aberto.

\section{Breve recorrido das ideias}

Para pensar temas dramatúrgicos a partir do processo de pesquisa-criação de O Retorno a Juberlano, neste artigo, delineou-se primeiramente, o lugar de fala da 
escrita, constituído no processo de interlocução poética (dramaturgismo) da pesquisa em Teatro de Objetos iniciada em 2017 pelo Grupo Ânima de Teatro de Animação. A partir desse lugar, foi apresentado a noção de escuta como princípio basal para o desenvolvimento do trabalho do dramaturgista, bem como para a pesquisa-criação no campo das Artes Cênicas, com agudo sentido ganho no campo do Teatro de Objetos. Aqui, há a aposta de que seu exercício, o da escuta, acontece com mais radicalidade quando do estabelecimento de outras relações entre homem e matéria, num intento de deslocar a assimétrica relação ancorada no antropocentrismo. Nessa reconfiguração das premissas hierárquicas homem-objeto, a escuta ganha contornos que se acirram no Teatro de Objetos para além das questões físicas, conectando-se ao aspecto social, no qual a dramaturgia é pensada conjuntamente com a memória coletiva do objeto. Esse contexto social do objeto, foi apresentado como um chão sobre qual fatores políticos relativos aos processos de industrialização, vinculam-se ao processo de emergência dessa linguagem do Teatro de Animação. Com a invasão de objetos industrializados, o Teatro de Objetos dá espaço a uma escritura poética, criando sentidos cênicos para o objeto ordinário.

A partir desse gesto de inscrição de sentido poético, o texto procurou estabelecer reflexões acerca de três terrenos dramatúrgicos no campo do Teatro de Objetos: antropo-zoomorfia, narrativo, físico-visual. Num diálogo com os autores elencados, o artigo foi traçando conexões entre esses modos de fazer dramaturgia nos dois primeiros terrenos, para finalizar, apontando, a partir da descrição reflexiva do trajeto de criação do grupo Ânima, o terceiro terreno dramatúrgico. O desejo era mesmo de partilhar um conjunto de reflexões emergidas nessa pesquisa artística, numa vontade de produzir premissas para o debate, com o intuito de fortalecer a pesquisa e desdobramentos nessa linguagem.

\section{Referências}

ANIMA, Grupo. Projeto Chico da Silva - o retorno a Juberlano: investigação sobre o teatro de objetos. Fortaleza: no prelo, 2017.

BOGART, Anne; LANDAU, Tina. The viewpoints book: a practical guide of viewpoints and composition. New York: Theatre Comunications Group, 2005.

CARRIGNON, Christian e MATTÉOLI, Jean-Luc. Le théâtre d'objet: à la recherche du théâtre $d$ 'objet. Paris: Ed. Themaa, Encyclopèdie fragmentèe de la marionnette, vol. $2,2009$.

CAVALCANTE, Caroline M. H. A interpretação com o objeto: reflexões sobre o trabalho do ator-animador. 134 p. Dissertação de Mestrado (Mestrado em Teatro) - Programa de Pós-Graduação em Teatro, Universidade do Estado de Santa Catarina, Florianópolis, 2008. 
DUVAL, Justine. Le parti pris des choses. França: 2012. Disponível em: <http://www. lintermede.com/theatre-objet-marionnettes-isabelle-bertola-paris-cuisine-manarf-analyse-critique-interview-piece.php> Acesso em: 28 abril 2018.

HERCÓleS, Rosa Maria. Formas de Comunicação do Corpo - Novas Cartas sobre a Dança. Tese de doutorado defendida no Programa em Comunicação e Semiótica, PUC-SP, 2005.

INGOLD, Tim. Estar vivo: ensaios sobre movimento, conhecimento e descrição. São Paulo: Vozes, 2015.

JURKOWSKI, Henryk. Métamorphoses: La marionnette au XX siècle. Tradução: Eliane Lisboa. Charleville-Mézières: Éditions Institut International de la Marionnette, 2000.

KARTUN, Mauricio. Móin - Móin: Revista de Estudos sobre Teatro de Formas Animadas. Jaraguá do Sul: SCAR/UDESC, ano 7, v. 8, 2011.

KERKHOVEN, Marianne Van. O processo dramatúrgico. In: CALDAS, Paulo; GADELHA, Ernesto. Dança e dramaturgia[s]. São Paulo: Nexus, 2016.

PASSOS, Eduardo. Metodologias e procedimentos para a criação e pesquisa em arte. Palestra no VII Simpósio Internacional Reflexões Cênicas Contemporâneas. Campinas: 2018. Disponível em: <https://www.youtube.com/watch?v=oOBMECOaXog\&list=PLkU1JoV0M3XkU6ASQgRA6qthHhHSqUkoy\&index=3> Acesso em: 12 abril 2018.

PLASSARD, Didier. Entre l'homme et la chose, Agôn. França: 2012. Disponível em: <http://agon.ens-lyon.fr/index.php?id=2259> Acesso em: 15 abril 2018

PORTAIL DES ARTES DE LA MARIONNETTE. Yves Joly, icône de la marionnette moderne malgré lui. França: 2017. Disponível em: <https://www.artsdelamarionnette. eu/focus/yves-joly/> Acesso em: 20 abril 2018.

SOTER, Silvia. Cartografia Rumos Itaú Cultural dança: formação e criação. Organização Christine Greiner, Cristina Espírito Santo e Sônia Sobral. São Paulo: Itaú Cultural, 2014.

Recebido em: 30/05/2018 Aprovado em: 11/07/2018 